\title{
AOR
}

Selected Papers of \#AolR2021:

The 22nd Annual Conference of the

Association of Internet Researchers

Virtual Event / 13-16 Oct 2021

\section{TECHNOLOGICAL AGNOSTICISM AND CLIMATE CHANGE: PLATFORM CULTURE ON TECHNOLOGY FORUM WHIRLPOOL}

\author{
Aleesha Rodriguez \\ Queensland University of Technology
}

\section{Introduction}

This paper explores the (limited) discussion of climate change within energy debates on Australian technology forum Whirlpool. These discussions are characterised by technological agnosticism, which is an attitude that no technology is "better" or "worthier" than any other because "different technologies have different strengths and weaknesses" depending on the application requirement (Gorton \& Lui, 2002, p. 556). Within these energy debates, I observed Whirlpool contributors depoliticise energy technologies by removing climate change as a factor when considering technology choices. I argue that the prevalence of technological agnosticism within these debates is not an example of climate change denial per se but a reflection of Whirlpool's platform culture which valorises traits of geek masculinity such as rationality and neutrality (Massanari, 2017).

This paper is part of a larger research project that mapped online public debates about what was, until August 2020, the world's biggest battery (Vorrath \& Parkinson, 2020). The inception of this big battery-now known as the Hornsdale Power Reserve-was generated through a wager on Twitter, in March 2017, when an Australian softwarebillionaire asked Tesla's CEO Elon Musk via a tweet if Tesla could build a 100megawatt battery in 100 days in South Australia to solve an ongoing power crisis. Musk set the wager when he claimed that Tesla will get the system built in 100 days or it would be free (Musk, 2017). In this research, I employed digital methods (Roger et al., $2015)$ to empirically detect, visualise, and analyse online public debates on two social media platforms: Twitter-the platform of the big battery's inception-and Whirlpool, an Australian technology forum where contributors engage in longer-term debates about Australia's energy transition. This research explores how publics on Whirlpool are "discursively and practically taking part in the low-carbon energy transition" (Ryghaug et al., 2018, p. 298) and considers how the platform culture shapes these debates. 


\section{Methods}

Whirlpool (https://whirlpool.net.au/) is an online forum that is typically used to crowdsource solutions to various problems. It was established in 1998 as a broadband internet community resource "devoted to keeping the public informed about the state of internet access in Australia" (Whirlpool, 2021). Today, Whirlpool hosts over 3.7 million discussion threads that centre predominately on technology concerns but also lifestyle topics. The breadth of thread topics illustrates how Whirlpool has normalised as a general community knowledge resource. Yet, at present, very little research has been conducted on Whirlpool and current studies have focused on the platform as a site to examine crowdsourcing information (Podkalicka et al., 2019). Thus, leaving a clear research gap to consider Whirlpool's platform culture.

The data collected and explored in this paper comes from four public Whirlpool threads. Using keywords identified during an initial exploratory phase, I queried thread titles in Whirlpool and identified four thread titles that were most appropriate for a close analysis based on a criteria of relating to the wager on Twitter or South Australia's power crisis and having a reply count over 100 . Using the Google Chrome extension Data Miner, I scraped all reply texts $(n=3,101)$ within the four threads including any URLs, as well as metadata such as username, user id, date and time posted. I then completed a close reading of all replies and conducted a thematic analysis by starting with broad open codes and refined these codes through an exploratory and iterative coding process (Charmaz, 2006).

\section{Findings}

When it came to debating different energy technologies and solutions, I found Whirlpool contributors use the phases "technology agnostic", "energy agnostic", and "technology neutral" to signal technological agnosticism. Overall, when technological agnosticism was expressed within these debates, I observed it intersecting with issues concerning the viability, reliability, affordability, and efficiency of technology and pushing against concerns regarding climate change.

In terms of viability, I observed Whirlpool contributors emphasise that any proposed technology needs to be feasibly deployed to address the current situation. For example, one contributor expressed "why can't we be energy agnostic and realise consumers will buy solar $+[\mathrm{sic}]$ batteries when its [sic] viable." Moreover, arguments by contributors such as keeping fossil fuel generation "until we can actually replace them with something useful", illustrates that a technology's viability is dependent on how quickly it can be deployed.

In respect to a technology's reliability and affordability, I often observed these issues expressed together. For example, one contributor declared that "I'm energy agnostic, I want the cheapest power that's reliable." While within a different debate about which technology would be best to transition the grid to $100 \%$ renewable, a contributor asserted "having a reliable affordable power grid is an important national priority" and that the technology choice did not matter so long as this priority was met. 
Lastly, with respect to efficiency, I observed this concern employed particularly to neutralise technology choices from the goal of addressing climate change through renewable energy adoption. For example, one contributor posted: "I must confess, my ideology is efficiency. I don't care if it is renewable or not but that it is efficient." This operationalisation of technological agnosticism creates tension in addressing climate change as it attempts to depoliticise technology choice.

\section{Discussion and conclusion}

The above findings provide insight into how Whirlpool contributors employ technological agnosticism within energy debates. In these debates, climate change is framed as a political position and something that needs to be removed as a factor in technology choice. I argue that the operationalisation of technological agnosticism within these Whirlpool debates is not an example of climate change denial, but rather of Whirlpool's platform culture, which promotes geek masculinity. Geek masculinity "revolves around the acquisition, sharing, and distribution" of knowledge and "a valorisation of masculinity masquerading as a peculiar form of 'rationality"' (Massanari, 2017, p. 332-333). By rationalising technology choice through technological agnosticism, Whirlpool contributors attempt to absolve themselves from the effects of their technology choice on climate change. As one contributor defended in a reply: "a lot of people will accuse me of being a coal lover but really I'm just energy agnostic." Like Reddit, Whirlpool's platform features-which includes pseudonyms and rating systems-propagates this platform culture. This raises critical questions for future research to explore how particular platform cultures shape energy debates and ultimately, attitudes and action towards climate change.

\section{References}

Charmaz, K. (2006). Constructing grounded theory: A practical guide through qualitative analysis. SAGE Publications Ltd.

Devine-Wright, P., Batel, S., Aas, O., Sovacool, B., Labelle Carnegie, M., \& Ruud, A. (2017). A conceptual framework for understanding the social acceptance of energy infrastructure: Insights from energy storage. Energy Policy, 107, 27-31. https://doi.org/10.1016/j.enpol.2017.04.020

Gorton, I., \& Liu, A. (2002). Software component quality assessment in practice. Proceedings of the 24th International Conference on Software Engineering ICSE '02. https://doi.org/10.1145/581339.581408

Massanari, A. (2017). \#Gamergate and The Fappening: How Reddit's algorithm, governance, and culture support toxic technocultures. New media \& society, 19(3), 329-346. https://doi.org/10.1177/1461444815608807

Podkalicka, A., Winfree, T., Wright, A., \& McGregor, J. (2019). Sharing advice online to foster sustainable homes. In P. Newton, D. Prasad, A. Sproul, \& S. White (Eds.), 
Decarbonising the built environment: Charting the transition (pp. 469-488).

Palgrave Macmillan. https://doi.org/10.1007/978-981-13-7940-6 25

Rogers, R., Sánchez-Querubín, N., \& Kil, A. (2015). Issue mapping for an ageing Europe. Amsterdam University Press.

Ryghaug, M., Skjølsvold, T. M., \& Heidenreich, S. (2018). Creating energy citizenship through material participation. Social Studies of Science, 48(2), 283-303. https://doi.org/10.1177/0306312718770286

Vorrath, S., \& Parkinson, G. (2020, August 21). Australia's Tesla big battery is no longer biggest battery in the world. RenewEconomy. https://reneweconomy.com.au/australias-tesla-big-battery-is-no-longer-biggestbattery-in-the-world-30125/

Whirlpool (2021). Whirlpool Knowledge Base. Whirlpool.https://whirlpool.net.au/wiki/ 